Published in final edited form as:

J Diabetes Complications. 2014 ; 28(3): 305-310. doi:10.1016/j.jdiacomp.2014.01.005.

\title{
No association of dietary fiber intake with inflammation or arterial stiffness in youth with type 1 diabetes
}

\author{
Lindsay M. Jaacks, B.S. ${ }^{a}$, Jamie Crandell, Ph.D. ${ }^{b}$, Angela D. Liese, Ph.D. ${ }^{c}$, Archana P. \\ Lamichhane, Ph.D. ${ }^{a}$, Ronny A. Bell, Ph.D. ${ }^{d}$, Dana Dabelea, M.D., Ph.D. ${ }^{e}$, Ralph B. \\ D'Agostino Jr., Ph.D. ${ }^{f}$, Lawrence M. Dolan, M.D. ${ }^{g}$, Santica Marcovina, Ph.D., D.Sc. ${ }^{h}$, Kristi \\ Reynolds, Ph.D.', Amy S. Shah, M.D.9, Elaine M. Urbina, M.D.9, R. Paul Wadwa, M.D.', and \\ Elizabeth J. Mayer-Davis, Ph.D. ${ }^{a, k}$ \\ aDepartment of Nutrition, The University of North Carolina, Chapel Hill, NC, USA \\ bDepartments of Nursing and Biostatistics, The University of North Carolina, Chapel Hill, NC, \\ USA \\ 'Department of Biostatistics and Epidemiology, The University of South Carolina, Columbia, SC, \\ USA \\ dDepartment of Epidemiology and Prevention, Wake Forest School of Medicine, Winston-Salem, \\ NC, USA \\ eDepartment of Epidemiology, The University of Colorado School of Public Health, Denver, CO, \\ USA \\ fDepartment of Biostatistics, Wake Forest School of Medicine, Winston-Salem, NC, USA \\ ${ }^{9}$ Cincinnati Children's Hospital Medical Center, Cincinnati, OH, USA \\ hDepartment of Medicine, The University of Washington, Seattle, WA, USA \\ 'Department of Research \& Evaluation, Kaiser Permanente Southern California, Pasadena, CA, \\ USA
}

jBarbara Davis Center for Diabetes, The University of Colorado School of Medicine, Aurora, CO, USA

kDepartment of Medicine, The University of North Carolina, Chapel Hill, NC, USA

\begin{abstract}
(C) 2014 Elsevier Inc. All rights reserved.

Correspondence to: Elizabeth J. Mayer-Davis, (phone) 001-919-966-7218, (fax) 001-919-966-7216, 135 Dauer Drive, Campus Box 7461, Chapel Hill, North Carolina 27599, USA, ejmayer_davis@unc.edu.

The contents of this paper are solely the responsibility of the authors and do not necessarily represent the official position of the Centers for Disease Control and Prevention and the National Institute of Diabetes and Digestive and Kidney Diseases.

Data from this study were presented at the 73rd Scientific Sessions of the American Diabetes Association, Chicago, Illinois, June 21 25, 2013.

Publisher's Disclaimer: This is a PDF file of an unedited manuscript that has been accepted for publication. As a service to our customers we are providing this early version of the manuscript. The manuscript will undergo copyediting, typesetting, and review of the resulting proof before it is published in its final citable form. Please note that during the production process errors may be discovered which could affect the content, and all legal disclaimers that apply to the journal pertain.
\end{abstract}


Aim-To examine the association of dietary fiber intake with inflammation and arterial stiffness among youth with type 1 diabetes (T1D) in the US.

Methods-Data are from youth $\geq 10$ years old with clinically diagnosed T1D for $\geq 3$ months and $\geq 1$ positive diabetes autoantibody in the SEARCH for Diabetes in Youth Study. Fiber intake was assessed by food frequency questionnaire with measurement error (ME) accounted for by structural sub-models derived using additional 24-hour dietary recall data in a calibration sample and the respective exposure-disease model covariates. Markers of inflammation, measured at baseline, included IL-6 ( $n=1405)$, CRP $(n=1387)$, and fibrinogen $(n=1340)$; markers of arterial stiffness, measured approximately 19 months post-baseline, were available in a subset of participants and included augmentation index $(n=180)$, pulse wave velocity $(n=184)$, and brachial distensibility $(n=177)$.

Results-Mean (SD) T1D duration was 47.9 (43.2) months; $12.5 \%$ of participants were obese. Mean (SD) ME-adjusted fiber intake was 15 (2.8) g/day. In multivariable analyses, fiber intake was not associated with inflammation or arterial stiffness.

Conclusion-Among youth with T1D, fiber intake does not meet recommendations and is not associated with measures of systemic inflammation or vascular stiffness. Further research is needed to evaluate whether fiber is associated with these outcomes in older individuals with T1D or among individuals with higher intakes than those observed in the present study.

\section{Keywords}

type 1 diabetes; youth; dietary fiber; inflammation; arterial stiffness

\section{Introduction}

A high-fiber diet may be protective against inflammation, which plays a key role in the development of atherosclerosis and subsequent vascular disease. Both observational and experimental studies among adults have reported an inverse relationship between dietary fiber and acute-phase inflammatory response markers, including interleukin 6 (IL-6) [1,2] and C-reactive protein (CRP) [2-4], and indicators of an abnormal prothrombotic state, such as fibrinogen [5,6]. Two recent studies among adolescents have also supported an inverse relationship between fiber intake and inflammation $[7,8]$.

A more limited literature exists on the relationship between dietary fiber and measures of subclinical vascular disease. An Australian study among overweight and obese adults showed a decrease in augmentation index (AIx), a measure of central vascular function, after 6 weeks on a fiber supplement relative to placebo [9], and a longitudinal observational study among adolescents and young adults in the Netherlands reported an inverse association between fiber intake and carotid artery distensibility [10].

Patients with type 1 diabetes (T1D) are at increased risk of cardiovascular disease (CVD): coronary heart disease occurs earlier and is associated with higher mortality among these individuals [11]. Indeed, decreased carotid artery distensibility [12,13] and brachial distensibility [14], and increased AIx [15] and carotid artery intima-media thickness [13,16] have been reported in children and adolescents with T1D. While dietary fiber has been 
linked to improved postprandial glycemia [17,18] and total cholesterol [19] among individuals with T1D, a potential protective effect of fiber on inflammation and subclinical vascular disease, particularly among youth, has yet to be confirmed. One observational study among adults with T1D reported an inverse association between dietary fiber intake and low-grade inflammation, quantified as an overall z-score of IL-6, CRP, and tumor necrosis factor a levels [20]. To our knowledge, only a single experimental study, conducted in 1981, has explored this relationship in youth with T1D, reporting a decrease in fibrinogen after 4 weeks on a diet supplemented with $0.45 \mathrm{~g}$ guar gum $/ \mathrm{kg}$ body weight/day [21]. If a protective effect of high-fiber diets on inflammation and subclinical vascular disease indeed exists, it would represent an important opportunity for early intervention to reduce CVD risk in this population. To address this gap in scientific knowledge, we evaluated the association of dietary fiber with inflammation and arterial stiffness among youth with T1D.

\section{Methods}

\section{Study Population}

Data are from SEARCH for Diabetes in Youth [22], which includes a cohort of youth diagnosed with diabetes at $<20$ years of age across 5 sites in the U.S. beginning in 2002. In 2001, prevalent cases were also identified. Participants were asked to complete an initial survey and after completion were invited for an initial study visit. Participants in the prevalent 2001 and incident 2002-2005 cohorts who completed the dietary intake assessment (restricted to those $\geq 10$ years old) and had $\geq 1$ inflammatory marker measured during this initial study visit, had a diabetes duration $\geq 3$ months, were positive for $\geq 1$ diabetes autoantibody (GAD65 and IA2), and had a complete covariate set were included in this analysis. The final sample size was 1405 . Study protocols were approved by Institutional Review Boards at all participating sites, and written informed consent was obtained for all participants $\geq 18$ years of age and parent/guardian permission and participant assent for participants $<18$ years of age.

\section{Dietary Intake Assessment}

A modified version of the Block Kid's Food Frequency Questionnaire (FFQ) was used to assess dietary intake in SEARCH participants $\geq 10$ years of age during the initial study visit [23]. The FFQ included approximately 85 food items for which information on consumption in the past week ("yes" or "no") was collected. For participants responding "yes", additional data on how many days in the past week the item was consumed and typical portion size were collected. The nutrient and portion-size databases were established using the Nutrition Data System for Research (Database 3, Version 4.05/33, 2002, Nutrition Coordinating Center, University of Minnesota, Minneapolis, Minnesota) and industry sources.

In order to address measurement error (ME) associated with the FFQ, a Dietary Assessment Calibration Subsample was conducted in the SEARCH Nutrition Ancillary Study that included 172 participants who completed the FFQ and then completed up to three 24-hour dietary recalls over the course of the following 30 days. From these data, models were constructed to predict 24-hour dietary recall intake (assumed to be unbiased) from intake assessed by FFQ and the respective exposure-disease model covariates. The application of 
this method has been discussed in detail elsewhere [24]. Because the inflammatory markers, AIx, and carotid-femoral pulse wave velocity (PWV) and brachial artery distensibility (BrachD) exposure-disease models had three different covariate sets, three ME-adjustment models were constructed. Based on the relationships estimated by these models, total energy (kcal/day) and fiber intake (g/day) in the SEARCH sample were predicted and these MEadjusted dietary intakes were used in their respective exposure-disease models.

Given that this is a sample of children and adolescents, and that fiber recommendations are given in units of $\mathrm{g} / 1000 \mathrm{kcal}$ [25], for descriptive purposes participant characteristics were presented according to quartiles of ME-adjusted fiber in units of $\mathrm{g} / 1000 \mathrm{kcal}$. The quartile cut points predicted using the inflammatory marker covariate set were used given that these quartile cut points were equivalent to those predicted by the PWV/BrachD covariate set and differed by only a tenth of a gram from those predicted by the AIx covariate set. All exposure-disease models specified ME-adjusted fiber in units of $\mathrm{g}$ /day (quartiles or continuous), controlling for ME-adjusted total energy intake (kcal/day).

\section{Outcome Assessment}

During the initial study visit, a fasting venipuncture was performed on metabolically stable participants, defined as no episode of diabetic ketoacidosis in the past month. Three inflammatory markers-IL-6, CRP, and fibrinogen — were analyzed in stored samples from this visit at the study Central Laboratory (Northwest Lipid Metabolism and Diabetes Research Laboratories, University of Washington, Seattle, Washington). Specifically, IL-6 was assayed using the Human Adipokine panel B (Millipore Inc., Billerica, Massachusetts) on a Bio-Plex suspension array system (Bio-Rad Laboratories, Hercules, California), and CRP and fibrinogen were analyzed using Siemens reagent on a Siemens BNII nephelometer (Siemens Healthcare Diagnostics Inc., Newark, Delaware).

As part of a pilot study on CVD, measures of arterial stiffness were also collected on a subset of participants at two SEARCH sites. This CVD pilot study visit took place, on average, $19.4 \pm 7.6$ months after the SEARCH initial study visit. BrachD, a measure of vascular function of a peripheral muscular artery, was measured using a DynaPulse Pathway instrument (Pulse Metric, Inc., San Diego, California). PWV, a measure of pulse propagation representing central arterial stiffness, and AIx, a measure of wave reflections, were assessed using a SphygomCor SCOR-PVx System (Atcor Medical, Sydney, Australia) [14]. AIx was normalized to a heart rate of 75 beats per minute and expressed as a percent (AIx-75).

\section{Covariate Assessment}

Self-reported demographic covariates included gender, race/ethnicity, and estimated total annual household income. Smoking and physical activity questions were derived from the national Youth Risk Behavior Survey [26]. Participants were classified as "Current smokers" if they self-reported having smoked cigarettes on at least one of the 30 days preceding the survey; "Past smokers" if they had tried smoking or had smoked regularly (at least one cigarette every day for 30 days) but were not current smokers; and "Never smokers" if they had never smoked a whole cigarette. Participants who self-reported 
participating in physical activity that made them breathe hard or sweat for at least 20 minutes, on average, 0-2 days per week were classified as "Physically inactive"; and 3-7 days per week as "Physically active".

Body mass index (BMI) was calculated as measured weight $(\mathrm{kg})$ divided by height squared $\left(\mathrm{m}^{2}\right)$, and obesity was defined as a BMI $\geq 95^{\text {th }}$ age- and sex-specific percentile for participants $\leq 20$ years of age and BMI $\geq 30 \mathrm{~kg} / \mathrm{m}^{2}$ for participants $>20$ years of age [27]. Systolic and diastolic blood pressure (SBP and DBP, respectively) were measured using a standard mercury sphygmomanometer in triplicate and the average was used in subsequent analyses.

\section{Statistical Analysis}

Log transformations were used to account for non-normality of the exposures (ME-adjusted energy and fiber intake) and the inflammatory marker outcomes (IL-6, CRP, and fibrinogen). Multivariable linear regression models were used to estimate the association of ME-adjusted dietary fiber intake with inflammation and arterial stiffness. Potential confounders were identified through a literature review and formally evaluated by assessing their relationships with the exposure and outcomes. The final adjustment set included MEadjusted total energy intake, age, gender, race/ethnicity, diabetes duration, smoking status, and physical activity. Models predicting the arterial stiffness outcomes (PWV, AIx-75, and BrachD) were additionally adjusted for the time between assessment of diet (SEARCH initial study visit) and arterial stiffness (CVD pilot study visit), and mean arterial blood pressure (to account for background distending pressure) calculated as [( $\times \mathrm{DBP})+\mathrm{SBP}]$ divided by 3 . Models predicting AIx-75 were also adjusted for height given that height directly influences the distance from the heart of wave reflection sites. As a sensitivity analysis, exposure-disease models stratified by soluble and insoluble fiber intake were also explored. All analyses were conducted using SAS 9.2 (SAS Institute, Cary, North Carolina). Values are presented as mean \pm SD or $\%$.

\section{Results}

Participants were $14.7 \pm 3.0$ years of age with a diabetes duration of $47.9 \pm 43.2$ months; $50.5 \%$ of participants were female (Table 1). The BMI-z score was $0.64 \pm 0.89 ; 12.5 \%$ of participants were classified as obese. Estimated total dietary fiber from the SEARCH FFQ was $13.6 \pm 7.1 \mathrm{~g} /$ day. Fiber intake was $14.7 \pm 2.8 \mathrm{~g} /$ day as predicted by the ME model applied to the inflammatory maker covariate set; $14.5 \pm 2.8 \mathrm{~g} /$ day for that applied to the AIx covariate set; and $14.5 \pm 2.8 \mathrm{~g} /$ day for that applied to the PWV and BrachD covariate set.

Participants who were female, older, had shorter diabetes durations, had never smoked or were former smokers, and who exercised 3-7 days/week were more likely to be in the highest versus lowest quartile of ME-adjusted fiber intake (Table 1). There were no differences in race/ethnicity, BMI-z score, SBP, or DBP across dietary fiber quartiles and no clear association with obesity status was observed.

Mean unadjusted levels of markers of inflammation and arterial stiffness did not differ across quartiles of ME-adjusted dietary fiber intake (Table 1). Controlling for confounding 
factors, multivariable linear regression models confirmed that ME-adjusted dietary fiber intake was not associated with markers of inflammation or arterial stiffness in this sample. This observation held true when fiber intake was specified as quartiles (Table 2; Model 1) or continuously (Table 2; Model 2).

When dietary fiber was stratified by solubility, though parameter estimates for soluble fiber intake were larger than those for insoluble fiber intake, effects remained nonsignificant (data not shown).

\section{Discussion}

No association was observed between dietary fiber intake and markers of inflammation or arterial stiffness among youth with T1D. While these results are in contrast with the preponderance of evidence relating to IL-6 and CRP among adults and adolescents without diabetes [1-4], the evidence remains mixed for fibrinogen. In the National Heart, Lung, and Blood Institute Family Heart Study, no association was observed between dietary fiber and fibrinogen [28]. A randomized crossover study among healthy adults did not find a difference at 4 weeks in fibrinogen between diets supplemented with cereal fiber (19 g/day) and control diets [29], and a parallel randomized controlled trial among overweight and obese adults reported no differences in IL-6, CRP, or fibrinogen at 3 months between diets supplemented with psyllium ( 7 or $14 \mathrm{~g} /$ day) compared to control diets [30]. Indeed, null results relating to the fiber-CRP relationship among adults have also been reported [2,31]. We suggest three primary hypotheses to explain these conflicting results: differences in 1) fiber dose, 2) fiber type, and 3) sample population.

\section{Fiber dose}

An important advantage of epidemiological studies is that they provide a "reality check" on whether exposures are occurring in the population such that one could anticipate the health benefits reported in clinical trials. Our results confirm that youth with T1D have low dietary fiber intakes relative to the current American Diabetes Association (ADA) recommendation of $14 \mathrm{~g} / 1000 \mathrm{kcal}$ [25]; in fact, the average dietary fiber intake was about half of what is recommended. Further, the dietary fiber intakes previously reported to have a protective effect against low-grade inflammation, CVD, and all-cause mortality among adults with T1D were substantially higher than the intakes in our sample population [20,32]. Our study therefore suggests that current fiber intakes of youth with T1D in the US may not be high enough to observe the previously reported protective effects of this nutrient.

\section{Fiber type}

Some studies have shown a stronger protective effect for soluble fiber compared to insoluble fiber [20,32]. However, our results remained non-significant when stratified by fiber solubility. Future research should explore the effects of specific types of fiber, considering not only solubility in water, but also microbial fermentation in the large intestine and viscosity, which may influence fiber action. Although the mechanisms underlying the potential beneficial effects of dietary fiber on proinflammatory and prothrombotic states have not been fully elucidated, a leading hypothesis involves the production of short-chain

J Diabetes Complications. Author manuscript; available in PMC 2015 May 01. 
fatty acids from fermentable dietary fiber in the gut. For example, butyrate inhibits the effect of nuclear factor- $\kappa \mathrm{B}$, resulting in an overall decrease in the proinflammatory state [33], and acetate and propionate reduce IL-6 mRNA and proteins [34]. Dietary fibers, such as $\beta$ glucans, may also interact directly with immunoregulatory cells, resulting in antiinflammatory phenotypes [35]. The mechanisms underlying a potential protective effect of dietary fiber on endothelial function have yet to be explored, but may be related to observed improvements in blood pressure, lipid profiles, and inflammation. In summary, though several biological mechanisms of specific fiber types have been explored, the mechanisms underlying previously observed inverse relationships between dietary fiber intake and inflammation and arterial stiffness are not well understood.

\section{Sample population}

To our knowledge, this is the first observational study to evaluate the association of dietary fiber with inflammation and arterial stiffness among youth with T1D. A recent observational study among 559 adolescents without T1D reported that dietary fiber intake was inversely associated with CRP and fibrinogen [8], but the levels of CRP and fibrinogen in their population were lower than those seen in our sample. The observed protective effect in their study was also of note given that the reported fiber intake was lower in their population compared to our sample. One explanation for these observations is that the higher level of systemic inflammation seen in adolescents with T1D may indicate that in this population there are factors with stronger causal effects on inflammation than dietary fiber, and this may mask any beneficial effects. Other study populations reporting protective effects of fiber on inflammation have included European adults with T1D (median disease duration of 14.4 years) in the EURODIAB cohort [20] and US adults in the NHANES cohort [3]. The variability in reported results from these diverse populations further justifies the need for population-specific research of the potential beneficial effects of dietary fiber on CVD risk.

A key strength of this analysis is the inclusion of multiple measurements of the outcomes of interest. Previous studies have focused on a single inflammatory marker, most frequently CRP due to its stability and ease of measurement. These CVD risk factors may be more strongly correlated with adverse outcomes compared to traditional risk factors, such as BMI. Another strength of this study was the inclusion of measures of arterial stiffness, an early marker of the development of vascular disease and therefore an important intervention point. Additionally, we used innovative methods to account for the ME associated with the FFQ, and therefore our estimates of fiber and energy intake are likely less biased than those reported in previous studies.

A limitation of this analysis is the potential for residual systematic error in estimated fiber intake that remains after ME-adjustment. Furthermore, we only had measures of the outcomes at a single timepoint (baseline for the inflammatory markers and approximately 19 months post-baseline for the arterial stiffness markers). The samples sizes, particularly for the measures of arterial stiffness, were small and therefore null findings may indicate a lack of power to detect an effect. Future analyses of the ongoing SEARCH Cohort Study will allow both longitudinal analyses and evaluation of the association with subclinical measures of vascular disease in a larger sample. However, the analysis presented here represents the 
best available evidence on the relationship between dietary fiber and markers of early vascular disease development in youth with T1D.

The low dietary fiber intakes observed among youth with T1D in the US are not associated with measures of systemic inflammation or vascular stiffness. Clinical and public health efforts should focus on increasing these disconcertingly low dietary fiber intakes to meet current recommendations. Future research should involve clinical trials exploring feasible doses among youth with T1D and prospective observational studies in adults with longer T1D durations.

\title{
Acknowledgments
}

The SEARCH for Diabetes in Youth Study is indebted to the many youth and their families, and their health care providers, whose participation made this study possible.

\begin{abstract}
The authors wish to acknowledge the involvement of General Clinical Research Centers (GCRC) at the South Carolina Clinical \& Translational Research (SCTR) Institute, at the Medical University of South Carolina (NIH/ NCRR Grant number UL1RR029882); Children's Hospital and Regional Medical Center (Grant Number M01RR00037); Colorado Pediatric General Clinical Research Center (Grant Number M01 RR00069) and the Barbara Davis Center at the University of Colorado at Denver (DERC NIH P30 DK57516); and the Institutional Clinical and Translational Science Award (CTSA), NIH/NCRR at the University of Cincinnati (Grant Number 1UL1RR026314-01).
\end{abstract}

Grant support: SEARCH for Diabetes in Youth is funded by the Centers for Disease Control and Prevention (PA numbers 00097, DP-05-069, and DP-10-001) and supported by the National Institute of Diabetes and Digestive and Kidney Diseases (NIDDK). The SEARCH Nutrition Ancillary Study (R01 DK 077949, PI Mayer-Davis) is funded by the NIDDK. The SEARCH CVD Ancillary Study (R01 DK 078542-01A2, PI Dabelea) is funded by the NIH. The SEARCH AIR Ancillary study (R01 ES 019168, PI Puett) is funded by the National Institute of Environmental Health Sciences. Site Contract Numbers: Kaiser Permanente Southern California (U48/CCU919219, U01 DP000246, and U18DP002714), University of Colorado Denver (U48/CCU819241-3, U01 DP000247, and U18DP000247-06A1), Children's Hospital Medical Center (Cincinnati) (U48/CCU519239, U01 DP000248, and 1U18DP002709), University of North Carolina at Chapel Hill (U48/CCU419249, U01 DP000254, and U18DP002708-01), University of Washington School of Medicine (U58/CCU019235-4, U01 DP000244, and U18DP002710-01), Wake Forest University School of Medicine (U48/CCU919219, U01 DP000250, and 200-2010-35171).

\section{References}

1. Chuang SC, Vermeulen R, Sharabiani MT, Sacerdote C, Fatemeh SH, Berrino F, et al. The intake of grain fibers modulates cytokine levels in blood. Biomarkers. 2011; 16(6):504-510. [PubMed: 21812595]

2. Ma Y, Hebert JR, Li W, Bertone-Johnson ER, Olendzki B, Pagoto SL, et al. Association between dietary fiber and markers of systemic inflammation in the Women's Health Initiative Observational Study. Nutrition. 2008; 24(10):941-949. [PubMed: 18562168]

3. Ajani UA, Ford ES, Mokdad AH. Dietary fiber and C-reactive protein: Findings from National Health and Nutrition Examination Survey data. J Nutr. 2004; 134(5):1181-1185. [PubMed: 15113967]

4. King DE, Egan BM, Woolson RF, Mainous AG 3rd, Al-Solaiman Y, Jesri A. Effect of a high-fiber diet vs a fiber-supplemented diet on C-reactive protein level. Arch Intern Med. 2007; 167(5):502506. [PubMed: 17353499]

5. Freitas RN, Luben R, Wareham NJ, Khaw KT. Relationship between plasma fibrinogen and fiber intake in the EPIC-Norfolk cohort. Eur J Clin Nutr. 2012; 66(4):443-451. [PubMed: 22113250]

6. Ludwig DS, Pereira MA, Kroenke CH, Hilner JE, Van Horn L, Slattery ML, et al. Dietary fiber, weight gain, and cardiovascular disease risk factors in young adults. JAMA. 1999; 282(16):15391546. [PubMed: 10546693] 
7. Hasson RE, Adam TC, Davis JN, Kelly LA, Ventura EE, Byrd-Williams CE, et al. Randomized controlled trial to improve adiposity, inflammation, and insulin resistance in obese AfricanAmerican and Latino youth. Obesity (Silver Spring). 2012; 20(4):811-818. [PubMed: 21293446]

8. Parikh S, Pollock NK, Bhagatwala J, Guo DH, Gutin B, Zhu H, et al. Adolescent fiber consumption is associated with visceral fat and inflammatory markers. J Clin Endocrinol Metab. 2012; 97(8):E1451-1457. [PubMed: 22593589]

9. Pal S, Khossousi A, Binns C, Dhaliwal S, Radavelli-Bagatini S. The effects of 12-week psyllium fibre supplementation or healthy diet on blood pressure and arterial stiffness in overweight and obese individuals. Br J Nutr. 2012; 107(5):725-734. [PubMed: 21787454]

10. van de Laar RJ, Stehouwer CD, van Bussel BC, te Velde SJ, Prins MH, Twisk JW, et al. Lower lifetime dietary fiber intake is associated with carotid artery stiffness: the Amsterdam Growth and Health Longitudinal Study. Am J Clin Nutr. 2012; 96(1):14-23. [PubMed: 22623748]

11. Dorman JS, Laporte RE, Kuller LH, Cruickshanks KJ, Orchard TJ, Wagener DK, et al. The Pittsburgh Insulin-Dependent Diabetes Mellitus (IDDM) Morbidity and Mortality Study. Mortality results Diabetes. 1984; 33(3):271-276.

12. Parikh A, Sochett EB, McCrindle BW, Dipchand A, Daneman A, Daneman D. Carotid artery distensibility and cardiac function in adolescents with type 1 diabetes. J Pediatr. 2000; 137(4): 465-469. [PubMed: 11035822]

13. Stakos DA, Schuster DP, Sparks EA, Wooley CF, Osei K, Boudoulas H. Cardiovascular effects of type 1 diabetes mellitus in children. Angiology. 2005; 56(3):311-317. [PubMed: 15889199]

14. Urbina EM, Wadwa RP, Davis C, Snively BM, Dolan LM, Daniels SR, et al. Prevalence of increased arterial stiffness in children with type 1 diabetes mellitus differs by measurement site and sex: the SEARCH for Diabetes in Youth Study. J Pediatr. 2010; 156(5):731-737. [PubMed: 20097360]

15. Haller MJ, Samyn M, Nichols WW, Brusko T, Wasserfall C, Schwartz RF, et al. Radial artery tonometry demonstrates arterial stiffness in children with type 1 diabetes. Diabetes Care. 2004; 27(12):2911-2917. [PubMed: 15562206]

16. Atabek ME, Kurtoglu S, Pirgon O, Baykara M. Arterial wall thickening and stiffening in children and adolescents with type 1 diabetes. Diabetes Res Clin Pract. 2006; 74(1):33-40. [PubMed: 16621108]

17. Giacco R, Parillo M, Rivellese AA, Lasorella G, Giacco A, D'Episcopo L, et al. Long-term dietary treatment with increased amounts of fiber-rich low-glycemic index natural foods improves blood glucose control and reduces the number of hypoglycemic events in type 1 diabetic patients. Diabetes Care. 2000; 23(10):1461-1466. [PubMed: 11023137]

18. Kinmonth AL, Angus RM, Jenkins PA, Smith MA, Baum JD. Whole foods and increased dietary fibre improve blood glucose control in diabetic children. Arch Dis Child. 1982; 57(3):187-194. [PubMed: 6280621]

19. Anderson JW, Zeigler JA, Deakins DA, Floore TL, Dillon DW, Wood CL, et al. Metabolic effects of high-carbohydrate, high-fiber diets for insulin-dependent diabetic individuals. Am J Clin Nutr. 1991; 54(5):936-943. [PubMed: 1659172]

20. van Bussel BC, Soedamah-Muthu SS, Henry RM, Schalkwijk CG, Ferreira I, Chaturvedi N, et al. Unhealthy dietary patterns associated with inflammation and endothelial dysfunction in type 1 diabetes: The EURODIAB Study. Nutr Metab Cardiovasc Dis. 2012; 23(8):758-764. [PubMed: 22795869]

21. Koepp P, Hegewisch S. Effects of guar on plasma viscosity and related parameters in diabetic children. Eur J Pediatr. 1981; 137(1):31-33. [PubMed: 6268414]

22. SEARCH Study Group. SEARCH for Diabetes in Youth: A multicenter study of the prevalence, incidence and classification of diabetes mellitus in youth. Control Clin Trials. 2004; 25(5):458471. [PubMed: 15465616]

23. Mayer-Davis EJ, Nichols M, Liese AD, Bell RA, Dabelea DM, Johansen JM, et al. Dietary Intake among Youth with Diabetes: The SEARCH for Diabetes in Youth Study. J Am Diet Assoc. 2006; 106(5):689-697. [PubMed: 16647326] 
24. Midthune D, Schatzkin A, Subar AF, Thompson FE, Freedman LS, Carroll RJ, et al. Validating an FFQ for intake of episodically consumed foods: Application to the National Institutes of HealthAARP Diet and Health Study. Public Health Nutr. 2011; 14(7):1212-1221. [PubMed: 21486523]

25. Bantle JP, Wylie-Rosett J, Albright AL, Apovian CM, Clark NG, et al. American Diabetes Association. Nutrition recommendations and interventions for diabetes: A position statement of the American Diabetes Association. Diabetes Care. 2008; 31(Suppl 1):S61-78. [PubMed: 18165339]

26. Brener ND, Kann L, Kinchen SA, Grunbaum JA, Whalen L, Eaton D, et al. Methodology of the youth risk behavior surveillance system. MMWR Recomm Rep. 2004; 53(RR-12):1-13. [PubMed: 15385915]

27. Barlow SE. Expert Committee. Expert committee recommendations regarding the prevention, assessment, and treatment of child and adolescent overweight and obesity: Summary report. Pediatrics. 2007; 120(Suppl 4):S164-192. [PubMed: 18055651]

28. Djousse L, Ellison RC, Zhang Y, Arnett DK, Sholinsky P, Borecki I. Relation between dietary fiber consumption and fibrinogen and plasminogen activator inhibitor type 1: The National Heart, Lung, and Blood Institute Family Heart Study. Am J Clin Nutr. 1998; 68(3):568-575. [PubMed: 9734732]

29. Fehily AM, Burr ML, Butland BK, Eastham RD. A randomised controlled trial to investigate the effect of a high fibre diet on blood pressure and plasma fibrinogen. J Epidemiol Community Health. 1986; 40(4):334-337. [PubMed: 2821151]

30. King DE, Mainous AG 3rd, Egan BM, Woolson RF, Geesey ME. Effect of psyllium fiber supplementation on C-reactive protein: The Trial to Reduce Inflammatory Markers (TRIM). Ann Fam Med. 2008; 6(2):100-106. [PubMed: 18332401]

31. Theuwissen E, Plat J, Mensink RP. Consumption of oat beta-glucan with or without plant stanols did not influence inflammatory markers in hypercholesterolemic subjects. Mol Nutr Food Res. 2009; 53(3):370-376. [PubMed: 18979504]

32. Schoenaker DA, Toeller M, Chaturvedi N, Fuller JH, Soedamah-Muthu SS, EURODIAB Prospective Complications Study Group. Dietary saturated fat and fibre and risk of cardiovascular disease and all-cause mortality among type 1 diabetic patients: The EURODIAB Prospective Complications Study. Diabetologia. 2012; 55(8):2132-2141. [PubMed: 22526612]

33. Zapolska-Downar D, Siennicka A, Kaczmarczyk M, Kolodziej B, Naruszewicz M. Butyrate inhibits cytokine-induced VCAM-1 and ICAM-1 expression in cultured endothelial cells: The role of NF-kappaB and PPARalpha. J Nutr Biochem. 2004; 15(4):220-228. [PubMed: 15068815]

34. Tedelind S, Westberg F, Kjerrulf M, Vidal A. Anti-inflammatory properties of the short-chain fatty acids acetate and propionate: a study with relevance to inflammatory bowel disease. World $\mathrm{J}$ Gastroenterol. 2007; 13(20):2826-2832. [PubMed: 17569118]

35. Wismar R, Brix S, Frokiaer H, Laerke HN. Dietary fibers as immunoregulatory compounds in health and disease. Ann N Y Acad Sci. 2010; 1190:70-85. [PubMed: 20388138] 


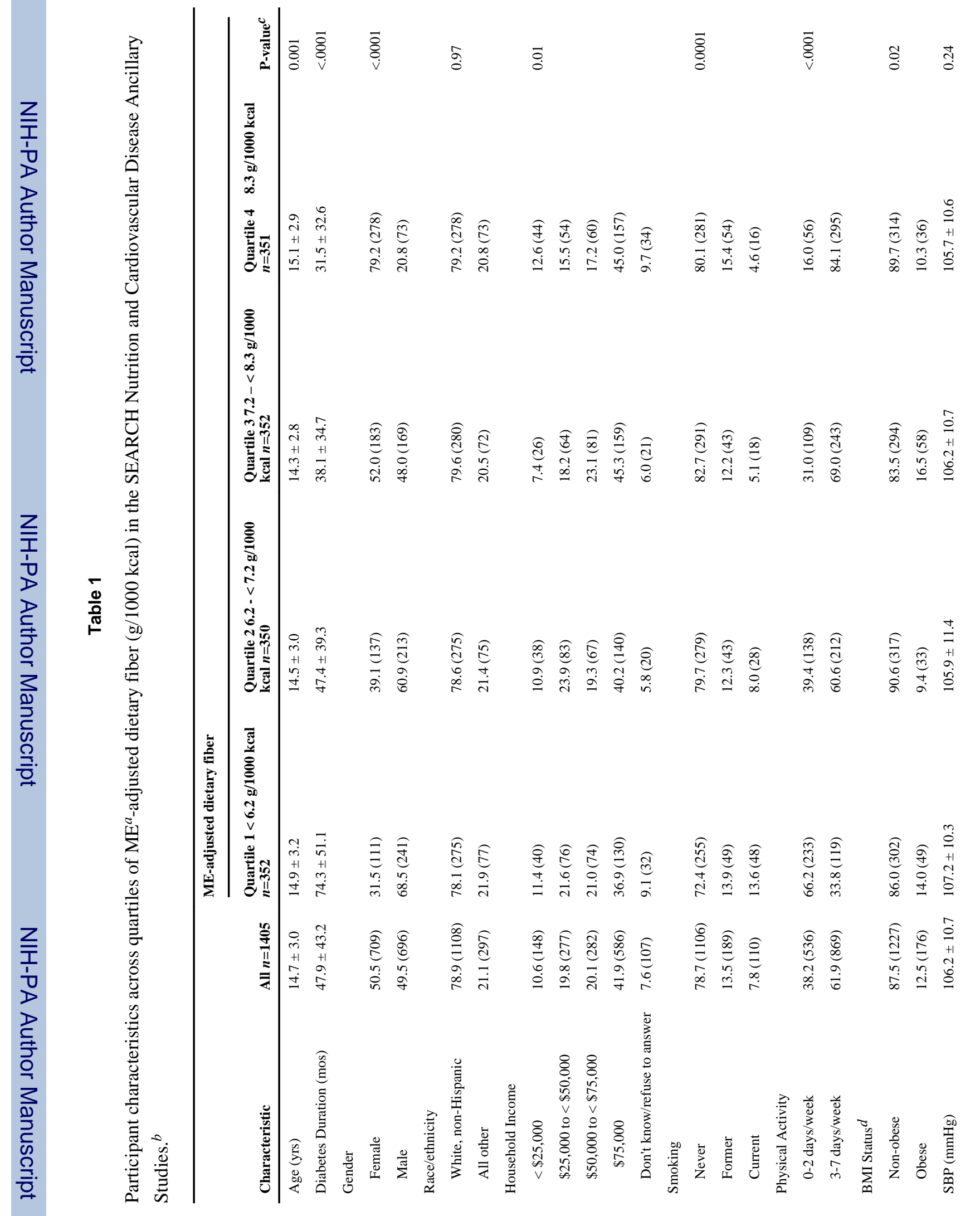




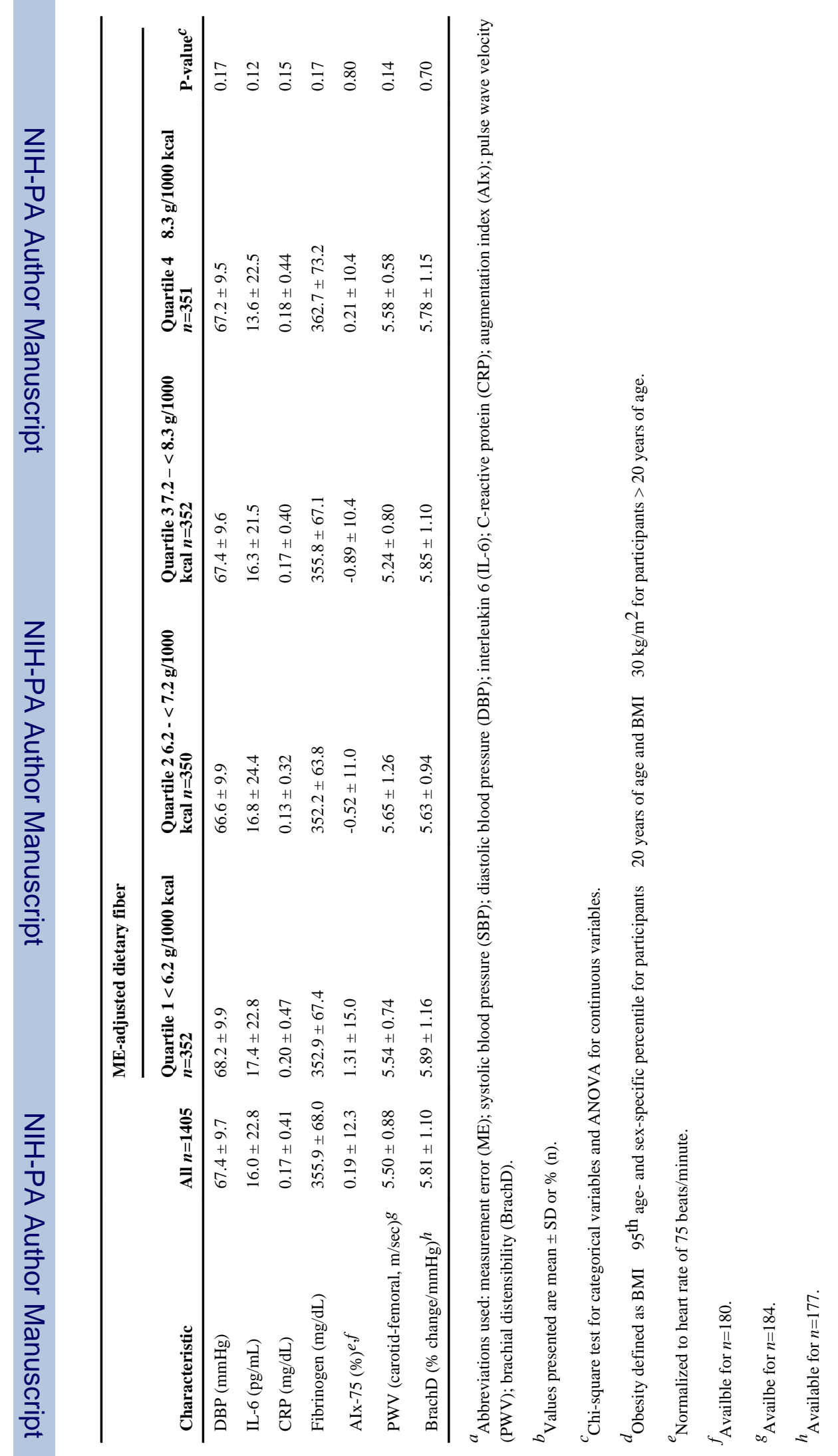

J Diabetes Complications. Author manuscript; available in PMC 2015 May 01. 


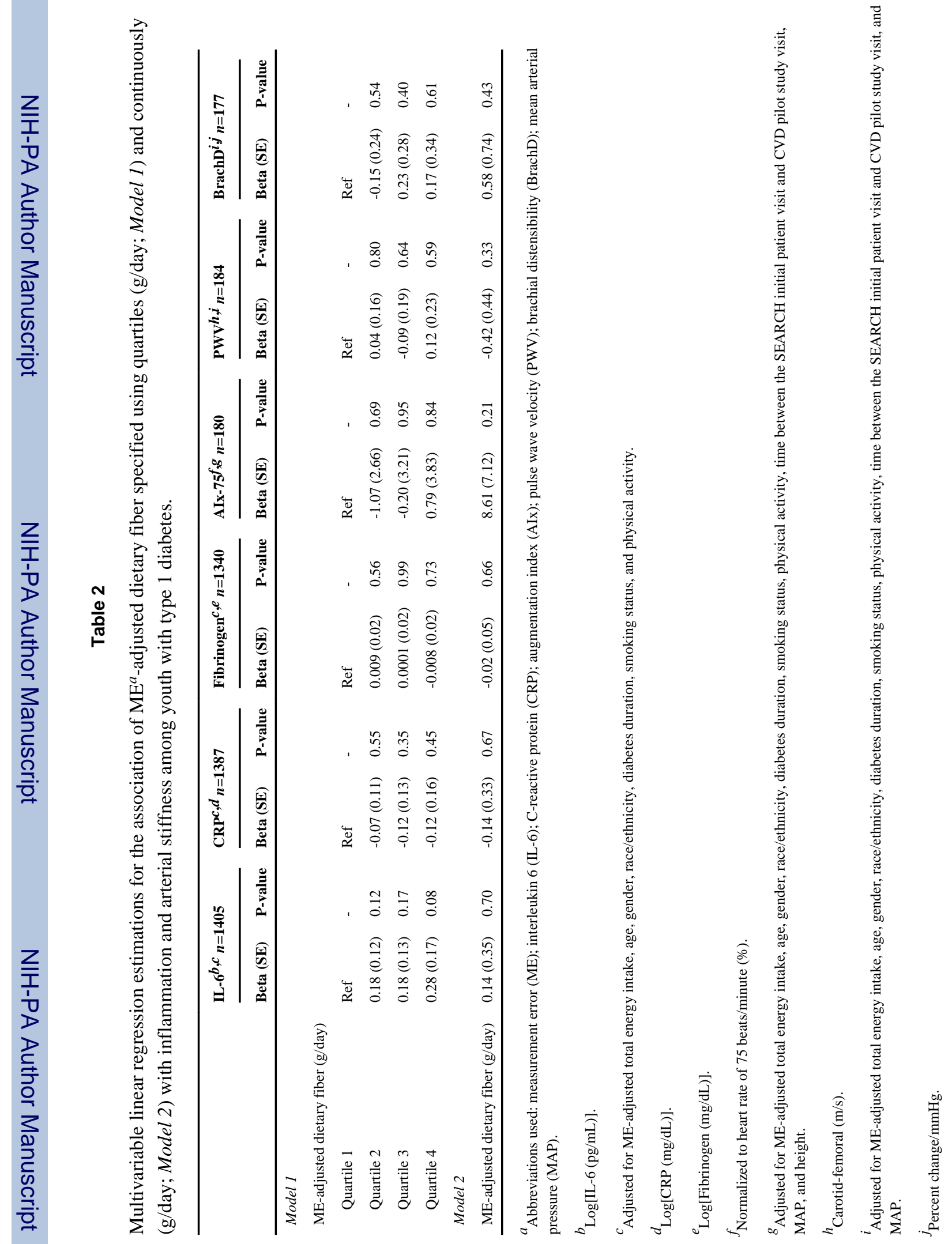

J Diabetes Complications. Author manuscript; available in PMC 2015 May 01. 